\title{
Artelogie
}

Recherche sur les arts, le patrimoine et la littérature de l'Amérique latine

17 | 2021

Transformaciones en Cuba contemporánea: cultura y sociedad

\section{Algunos videastas jóvenes camagüeyanos}

Rafael Almanza

\section{(2) OpenEdition}

\section{Journals}

Edición electrónica

URL: https://journals.openedition.org/artelogie/9725

DOI: 10.4000/artelogie.9725

ISSN: 2115-6395

Editor

Association ESCAL

Referencia electrónica

Rafael Almanza, «Algunos videastas jóvenes camagüeyanos», Artelogie [En línea], 17 | 2021, Publicado el 27 septiembre 2021, consultado el 15 septiembre 2022. URL: http://journals.openedition.org/ artelogie/9725 ; DOI: https://doi.org/10.4000/artelogie.9725

Este documento fue generado automáticamente el 15 septiembre 2022.

All rights reserved 


\title{
Algunos videastas jóvenes camagüeyanos
}

\author{
Rafael Almanza
}

\section{Algunos videastas jóvenes camagüeyanos}

1 Camagüey, una ciudad de más de trescientos mil habitantes en el centro de la Isla de Cuba, ha sido la ciudad primada de la poesía, del pensamiento económico, y de la idea civil y democrática de la nación. Habiendo huido del mar por la presión de los piratas, la antigua villa, una de las primeras siete fundadas por los españoles, aprendió a vivir de sí y a existir con independencia, incluso de las formas de existir y pensar del resto del país. Ningún dictador, ninguna figura autoritaria salió jamás de este sitio. Su figura militar insigne, el Mayor General Ignacio Agramonte, muerto en combate en plena juventud, fue precisamente el fundador de la democracia cubana, celoso defensor de las libertades aun en tiempo de guerra. Los camagüeyanos hemos vivido durante siglos con una diferencia, hasta con un enfrentamiento con el resto de las provincias cubanas, sin perder al mismo tiempo el patriotismo y la responsabilidad por los demás. Esta ciudad que tiene el culto de la libertad ha sido al mismo tiempo un bastión de la fe religiosa: sus sacerdotes católicos y protestantes resistieron exitosamente la ofensiva del ateísmo comunista y finalmente han vencido, pues proclamarse ateo no es precisamente hoy en día una costumbre popular en Camagüey. La creatividad de sus ciudadanos en cualquier ámbito de la cultura es conocida. Fue la segunda ciudad donde se hizo cine en Cuba, a principios del siglo $\mathrm{XX}$, y mantuvo durante décadas la segunda cinemateca en importancia del país. No es de extrañar que tenga un Festival Internacional de Videoarte bianual y que la creación de audiovisuales se haya disparado en los últimos años en el territorio, a medida que aparecían, a fuerza de tesón y sacrificio, los medios tecnológicos necesarios para emprender esa aventura, en medio de la miseria y la crisis 
permanente del socialismo agonizante. Salvo dos o tres excepciones, si es que hay tantas, este desafío ha sido asumido por la santa locura juvenil, por muchachos de menos de treinta y a menudo de menos de veinte años, hambreados y mal vestidos, habitantes de casas ruinosas o mediocres, censurados desde afuera y desde adentro como cualquiera, sin más guía que la pasión de crear y sin más información que la que se busca sin tener con qué. Es así que en los últimos diez años hemos visto nacer en Camagüey una cohorte de creadores audiovisuales casi todos muy jóvenes, que van teniendo ya una obra reconocida por su valor y por hacer la diferencia con respecto a lo que se hace a lo largo de la Isla. Atender a estos jóvenes hoy es empezar a disfrutar a maestros futuros, como ha ocurrido constantemente con el arte cubano de todos los tiempos.

2 Voy pues a referirme a un grupo de esos muchachos, no a todos. Atiendo preferentemente a estos no por ser mis amigos, o por que conozca mejor la obra de ellos que la de otros, aunque ambas razones son innegables y las considero válidas, sino porque encuentro en ellos una coherencia de grupo, unas constantes compartidas que no afectan la individualidad de la obra, como suele pasar con una generación. Los declaro videastas para identificar el soporte con el que trabajan, aprovechando su flexibilidad: videoarte, documental, corto de ficción e incluso largometraje, pues muchos aspiran a ser cineastas propiamente dichos: y ténganse en cuenta que la mayoría ejerce las artes plásticas, que han estudiado profesionalmente, en los géneros de pintura, dibujo e instalación. Este abanico de intenciones y habilidades puede hallarse también en cualquier parte del mundo globalizado; pero lo que unifica al grupo es la insólita seriedad de sus proyecciones, al margen de la banalidad, la competencia de modas y la imitación de modelos foráneos que caracteriza a un excesivo número de videastas cubanos. Para estos autores la tradición del arte serio no ha muerto, tal vez porque nacieron en una ciudad estancada en el mundo pre moderno y han pasado por la experiencia demoledora del socialismo. Pero se trata de una lealtad perfectamente contemporánea no solo por su originalidad y frescura: también por cuestionarse a sí mismos con los saludables recursos de la crítica. El video que mejor caracteriza esta orientación es Cuentos de mamá pelícano. Vigor y decadencia del símbolo, de Lester Álvarez (1984), el autor de mayor edad. Concebido como una improvisación para la exposición Cualsea, de abril de 2014, en la que el grupo mostró por primera vez su fuerza conjunta, el autor ironiza el propio lugar en el que se efectuó la muestra, las ruinas de la Logia de la Perseverancia de Camagüey, cuyo símbolo era la madre pelícano que se desgarra el pecho para alimentar a sus tres hijos. Vemos al autor en una atmósfera de disipación vulgar en un club nocturno camagüeyano, y también a dos de sus amigos mayores en sus casas: uno de ellos soy yo, que aparezco primero como prospecto de ruina humana y luego como golden teacher. A pesar de la música juvenil, el aire de ligereza y de impromptu, y las ironías incesantes, este videoarte vigoroso está lejos de abolir el símbolo: lo añora y lo prolonga con alegría. El ataúd, otro interesante trabajo de Álvarez, nos muestra el indeseable objeto balanceándose como hamaca en un jardín. En La vitrina que cae, otro ejemplo de la destreza del autor para sacar contenidos de una imagen sencilla, el desplome de los vidrios nos deja en una atmósfera contemplativa de múltiples resonancias existenciales, éticas y, para los cubanos, políticas. La vitrina... fue una videoinstalación de origen performático, puesto que fue filmada en público mientras la vitrina se desplomaba, y luego se proyectó sobre la misma pared donde estuviera colgada y encima de sus restos. Lester Álvarez, pintor, curador, crítico, documentalista, líder de artistas, está concluyendo ahora su primer largometraje de 
ficción sobre soporte digital, La humillación, una investigación de ese estado de ánimo tan conocido por los cubanos, pero con una óptica universal. Esta es la otra característica importante del grupo: intenta siempre ver su propia circunstancia sin ataduras nacionales, sin compromisos políticos explícitos, pero también muy distante de la pretensión de ser primermundistas extraviados por cortesía en un ámbito ajeno. La lectura universal y la encarnada en su circunstancia coinciden con una lucidez natural, sello de siempre de la obra de arte verdadera.

3 Si hay un autor que ejemplifica esta característica es Adrian Curbelo (1990), el más centrado en el género del videoarte. División de la naturaleza, su primer video de importancia, conforma un espacio de misterio y drama con unos pocos elementos de imagen y actuación, sostenidos con intensidad contemplativa sobre unos cuatro minutos y medio de silencio. La cámara como ojo investigador, como ojo de Dios o del hombre espiritual que se interroga por su propio ser y por el Ser, revela un drama mudo, inexpresable, aunque nunca trágico. Esa misma disposición reflexiva de la cámara no se atiene solo a la intemperie del ser universal, como ocurre también en La silla, video circular en picada donde un joven fracasa una y otra vez, en trescientos sesenta grados, en la simple opción de sentarse, sino que puede atenerse a lo histórico concreto hasta el nivel de la denuncia en Pecera, un video difícil de evaluar en todo su valor si desconocemos la realidad cubana de la que parte: la piscina del hotel Meliá Cohiba en La Habana. Aquí la cámara filma la trivialidad de la piscina de este gigantesco, ostentoso y vulgar hotel de primera clase para extranjeros que lo paguen, tan caro como mal construido, hasta el punto de que tras el muro de la piscina mediocre hay que sufrir unos edificios populares todavía más horribles. Para bañarse en la piscina hay que decidirse a ignorar esa fea, culpable presencia. Pero es desde ahí, desde el sitio del pueblo, donde la cámara finalmente capta la indiferencia del turista, el descaro y la incapacidad de los dueños. Esta denuncia construida con solo imagen y ruido ambiente, otra vez explotando además las posibilidades del silencio, hace homenaje a las mejores posibilidades del video y constituye además un testimonio de valor antropológico, que crecerá con los años. Esas virtudes se amplían con voz y texto en Última cinta, un corto en el que, durante diez minutos, vemos exactamente el mismo encuadre que nos muestra una maleta frente a un ventanal que da a un balcón de un rincón cualquiera de La Habana. La imagen y su persistencia aluden a la necesidad de huir de una realidad agobiante, intolerable. Es lo que el joven personaje que entra y sale del encuadre como una sombra nos confiesa en esa cinta de antiguo video tape, rebobinada incesantemente, como en la búsqueda de un sentido o de un coraje. Los cuatro espléndidos videos se atreven además a una perfecta coherencia de estilo: sobriedad, tratamiento intenso de los recursos y los temas, huida de cualquier afectación o moda. En Adrian Curbelo la reticencia, lo no dicho, es lo que más dice. Notable para un videasta que maneja la palabra, que escribe narrativa. Le interesa la realidad del sufrimiento, asunto inaguantable para la frivolidad de cualquier época, pero garantía de gran arte y de salvación.

4 Del más joven de la tríada, Kevin Ávila (1994), comentaré por voluntad suya solo dos videos muy distintos, que ejemplifican la versatilidad del autor, que también dibuja, pinta e instala. Ha filmado cortos de ficción y clips, y se distingue especialmente en el videoarte. Cinestesia no debe engañarnos con ese título que, aunque irónico, apuntaría hacia un ejercicio formal de las relaciones entre imagen y sonido, en este caso fragmentos de piezas de maestros del jazz. Investigación de la vida doméstica, encarnada en la casa y la madre del autor, nos la presenta en verdad como todo lo 
contrario de lo que creemos y de lo que la relajada música nos propone: nunca banalidad, sino misterio. Las realidades que la cámara en mano va grabando resultan de lo más corrientes, pero la fijeza en ellas y el movimiento incesante y aparentemente absurdo del encuadre van aportando una extrañeza, risueña y por eso mismo profunda, del ser aquí. La escena Las siamesas, en la que la madre corta la carne de cerdo en la cocina y la gata la acosa con el hambre, impacta con el develamiento de lo que hemos visto mil veces sin ver: la brutalidad de la carne, del animal que mata y come, del hambre frustrada que somos. La vida doméstica, en apariencia un refugio contra la locura del mundo, se nos devela como un milagro al revés, como siamesas que hay que cortar despiadadamente, no para otro fin que para el de obtener más soledad y más ignorancia, como encontramos en la sección final, La entrevista. Que un muchacho de veinte años haya logrado estas sutilezas con apenas una cámara en la mano en su propia casa, supone una sabiduría natural para enfrentar la realidad y las posibilidades del arte. Y aun es capaz de lanzarse a la complicación contraria en The big dream. En este documental vuelve aparecer la mamá del autor, pero ahora en la calle enfrentándome a mí mismo durante mi performance Crimea es del que más mea, concebido para la ya citada muestra Cualsea. Es la salida de la casa, el enfrentamiento al salvajismo de la historia, a la indiferencia por sí mismo, y por el prójimo como persona y como nación; y es también el encuentro con una filiación más amplia que la de la familia: la de las patrias y sus ciudadanos magnos, y sus hermanos y hermanas. Como mi performance era de tipo humorístico, el autor pudo conectar con estas evidencias que no lo son tanto para una mente como la suya, como la de todo el grupo, despegada y crítica. Esta vez tuvo que partir de imágenes pobremente obtenidas por otras personas y las usó con maestría, aunque no dejo de lamentar la ausencia de un brillantísimo pasaje de cámara en mano propia que finalmente decidió no usar. El joven edita con un cuidado exquisito y tiene un sentido muy sutil del tempo. Cinestesia y The big dream construyen un díptico de opuestos, unificados por el poder del arte para develar las esencias, y para salvarlas en el alma.

Me siento casi como un delincuente al tener que detener aquí la lista de los videastas que comento. Pero es imposible que no mencione al menos a Rolando González (1989), tan afín al grupo que su primer video se titulaba precisamente $E l$ sentido, y que añade a él, en El recinto, el trabajo en 3D con finas ambiciones filosóficas; Samir Bernárdez (1988), tan dotado de eficaces preguntas como cualquiera de estos muchachos, y con una notable destreza para obtenerlo de la casi nada: los reflejos en el agua de Iniciación; Hamlet Armas (1989), cuyo gusto por el videoarte compuesto de fotografías o planos de encuadre fijo en el estilo de dos canales nos invita a una complejidad de visión y reflexión que pasa por el compromiso con la libertad del espectador; y Louis Arturo Aguirre (1991), que añade a la variedad de técnicas del grupo el stop motion de Oso de cuna, un ácido comentario sobre los malos padres. A Marya Yaborskaya (1987), camagüeyana domiciliada en París, más orientada hasta donde conozco hacia la ficción que al videoarte propiamente dicho, la tengo entre las personalidades más robustas de la imagen en Cuba: me abstengo de comentarla en detalle porque no he visto sus últimas obras. Su corto Ordalía, apenas un ejercicio de su escuela de cine parisina, despliega una intensidad de expresión inédita en nuestro país: su seriedad no es filosófica sino subjetiva, pero precisamente en eso se revela como mujer poderosa y como artista real. Camagüey, la más criolla de las ciudades cubanas según Guillermo Cabrera Infante, y siempre ganosa de futuro, tiene un futuro en el video. Estos ocho jóvenes, que serán asediados en breve por la emergencia de nuevos nombres, son 
buenos ejemplos de la ofensiva del video cubano, no por alcanzar el estándar mundial, sino por establecer sus propias cumbres, desde la identidad y la sinceridad del talento.

6 Camagüey, 6 de septiembre de 2016 (texto inédito)

\section{RESÚMENES}

Cet article présente les avancées de la recherche sur la législation culturelle concernant les artistes, sous les gouvernements du Frente Amplio, en Uruguay. À cette fin, les procès-verbaux de la commission de la culture et la discussion parlementaire concernant le statut de l'artiste et des métiers connexes approuvés en 2008 ont été analysés et les données du ministère du Travail sur le registre des artistes ont été systématisées. Les deux manières d'aborder le sujet nous ont permis de savoir combien sont les artistes inscrits et leurs profils et les positions de certains législateurs dans la discussion parlementaire. Les résultats montrent à quel point cette législation est peu connue des artistes et de la société. Cela entrave et retarde les nouvelles réalisations législatives plus inclusives.

\section{ÍNDICE}

Mots-clés: législation culturelle, artistes, droits, statut, Uruguay

Palabras claves: Camagüey, Cine cubano, Lester Álvarez, Adrian Curbelo, Kevin Ávila, Rolando González

\section{AUTOR}

\section{RAFAEL ALMANZA}

Rafael Gabriel Almanza Alonso (Camagüey, Cuba, 1957) es un intelectual cubano, poeta, investigador de la obra de José Martí, narrador, crítico literario y de arte, libretista de ópera, animador cultural, curador, periodista independiente, editor, y maestro de escritores, artistas y periodistas. Algunas de sus obras son : En torno al pensamiento económico de José Martí (ensayo) 1990; El octavo día (cuentos) 1998; Hombre y tecnología en José Martí (ensayo) 2001; Libro de Jóveno (poesía) 2003; El Gran Camino de la Vida (poesía) 2005; Los hechos del apóstol (ensayo) 2005; Vida del Padre Olallo 2005; Elíseo Diego: el juego de dies? (ensayo) 2008; Hymnos (poesía) 2014. rafagacu12@gmail.com 